www.jmscr.igmpublication.org Impact Factor 5.244

Index Copernicus Value: 83.27

ISSN (e)-2347-176x ISSN (p) 2455-0450

crossref DOI: _https://dx.doi.org/10.18535/jmscr/v4i12.40

Journal Of Medical Science And Clinical Research

\title{
Inguinal Hernia Repair: Comparison of Local Anaesthesia and Spinal Anaesthesia
}

Authors

\author{
Dr Amul Bhedi ${ }^{1}$, Dr Sushil Damor ${ }^{2}$, Dr Arnab Sarkar ${ }^{3}$
}

${ }^{1}$ Associate Professor, Department of General Surgery, Medical College and S.S.G. Hospital, Baroda

${ }^{2}$ Assistant Professor, Department of General Surgery, Medical College and S.S.G. Hospital, Baroda

${ }^{3}$ Resident Doctor, Department of General Surgery, Medical College and S.S.G. Hospital, Baroda

Corresponding Author

Dr Amul Bhedi

Address: 12, Alok Residency, Opp. Vaikunth-2, Khodiyar Char Rasta, New VIP Road, Vadodara- 390019.

Email: amul_bhedi@yahoo.com

\begin{abstract}
Background: Inguinal hernia repair remains one of the most commonly performed operations worldwide. Today, local anaesthesia is the most preferred type over spinal and general anaesthesia in day-case hernia surgeries. Advantages being postoperative pain relief, early ambulation, shorter hospital stay and lesser costs. The condition of patient, surgeon's experience and technical factors also play a role in this. Hence, this study will help us to discuss the factors that can help us to decide the effectiveness of local anaesthesia in day-case hernia surgeries.
\end{abstract}

Aims and Objectives: To determine whether local anaesthetic technique was an acceptable alternative to spinal anaesthesia for hernia repair, especially with regards to operative condition, patients \& surgeons satisfaction, postoperative pain relief \& complications and economical benefits.

Settings and Design: This was a prospective clinical study consisting of 60 patients undergoing Lichtenstein's inguinal hernia repair, out of which 30 were given local anaesthesia and 30 were given spinal anaesthesia. All patients admitted in Department of General Surgery, SSG Hospital, Vadodara attached to the Medical College Baroda from September 2007 to January 2008.

Materials and Methods: Data was collected by meticulous history taking, careful clinical examination, appropriate radiological, haematological investigation, operative findings and follow-up of the cases.

Results: Immediate post-operative pain relief was more in LA group as compared to SA group, whereas after 24 hours, there was no significant difference in the pain scores between the two groups. Only three patients in SA group had micturition complaints post-operatively. Recovery from anesthesia was significantly faster for patients in the LA group than those in the SA group which had a mean interval of 4.1 hours. There was no significant difference in operative time and duration of hospital stay in the two groups.

Conclusion: It can be reliably concluded that local anaesthesia can be a preferred method in day-case hernia surgeries owing to its advantages. However, the experience of the surgeon and proper participation by the patient should also be looked upon in such cases.

Keywords: Inguinal hernia, Local anaesthesia, Spinal anaesthesia, Pain, Hernioplasty, Day-case surgery. 


\section{Introduction}

Sir Astley Paston Cooper has perfectly described as "no disease of the human body belonging to the province of the surgeon requires in its treatment a better combination of accurate anatomical knowledge with surgical skills than hernia in all its varieties." Inguinal hernias are one of the most common problems encountered by the surgeon accounting for about $10-12 \%$ of all patients.

Inguinal hernia repair, one of the most commonly performed operations world-wide, can be done under general anaesthesia, spinal / epidural anaesthesia \& local anaesthesia depending upon a variety of factors viz. surgeon's wish, patient's acceptance, safety, feasibility \& cost, etc. ${ }^{(1,2,3)}$

Recently there has been revival in the use of local anaesthetic technique for herniorrhaphy. ${ }^{(4,5,6)}$ Several retrospective and randomised controlled trials have shown that local anaesthesia provides the best clinical and economic benefits to patients. Obviously, the choice of anaesthesia will be influenced by patient preferences and needs and also by local resources and skills.

In private, specialized hernia centers, local anesthesia (LA) is often preferred for day-case open hernia repair because of its simplicity, low cost, and lack of potentially detrimental cardiovascular effects observed with regional or general anesthesia $(\mathrm{GA}){ }^{(7,8)}$

The present study was designed to determine whether local anaesthetic technique was an acceptable alternative to spinal anaesthesia for hernia repair, especially with regards to operative condition, patients \& surgeons satisfaction, postoperative pain relief \& complications and economical benefits.

\section{Materials and Methods}

This is a comparative study carried out in 60 patients admitted in surgical ward in Sir Sayajirao Hospital, Baroda from January 2007 to September 2008. All patients of more than 18 years having uncomplicated inguinal hernia are included in this study. Patients with recurrent, bilateral, irreducible, strangulated, incarcerated, obstructed hernia, obese patients are excluded in this study. By simple randomization, patients were divided into two groups; thirty of them receiving local anaesthesia and another thirty receiving spinal anaesthesia. A written informed consent was obtained from patients and data was collected on printed proforma including age, gender, and occupation, history of swelling in inguinal region, COPD, jaundice, previous abdominal surgery, obesity and concomitant diseases. Hemogram, random blood glucose, liver and renal function tests, chest radiograph and ECG were done in all patients from surgical and anaesthetic point of view. Patients aged more than 50 years underwent digital rectal examination and ultrasonography for evaluation of the prostate.

All the patients who were finally enlisted for surgery were tested for sensitivity to lignocaine and bupivacaine by an intradermal skin test after the preanesthetic assessment one day prior to surgery.

\section{Technique of Anesthesia}

For the $S A$ group, administration of the anesthetic and intra-operative monitoring was done by an anesthesiologist. Pre-medication was given with Glycopyrolate, Ranitidine and Perinorm. Sedation was not utilized.

For the LA group, administration of the anaesthetic regimen and intra-operative monitoring was done by the surgeon without the attendance of an anaesthesiologist. Pre-medication or sedation was not utilized.

The local anaesthetic drug was prepared as follows -

2\% lignocaine hydrochloride IP $\quad 17.5 \mathrm{ml}$

$0.5 \%$ bupivacaine hydrochloride IP $17.5 \mathrm{ml}$

Sterile Water for Injection IP $\quad 35 \mathrm{ml}$

$7.5 \% \mathrm{w} / \mathrm{v}$ Sodium Bicarbonate BP $4 \mathrm{ml}$

Adrenaline Tartarate (1:1000) IP $0.2 \mathrm{ml}$

Total volume of drug $\quad 75 \mathrm{ml}$ 
Placement of Local Anaesthesia

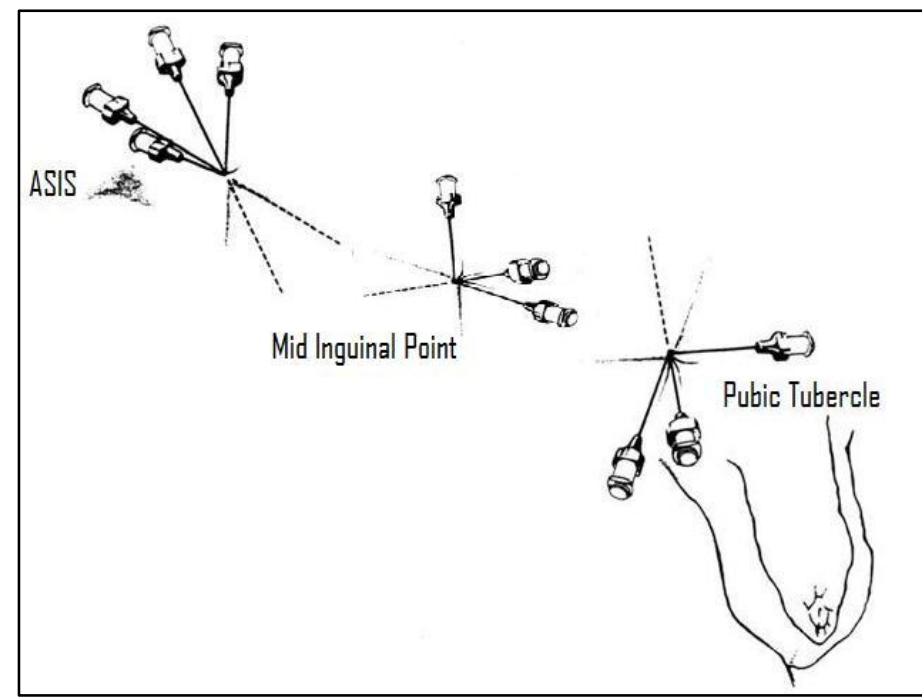

Figure 1: Placement of local anaesthesia

From a point approximately two centimeters medial to the anterior superior iliac spine, $10 \mathrm{ml}$ of local anesthetic is given under the external oblique in a fanwise fashion. Another $10 \mathrm{ml}$ of the drug is injected at the same site in the subcutaneous tissue, more towards the pubic tubercle along the proposed line of incision. Then the pubic tubercle is located by palpation. $10 \mathrm{ml}$ of the drug is injected at the pubic tubercle and towards the umbilicus along the rectus sheath to counteract the innervation from the contralateral side. A further $10 \mathrm{ml}$ of the drug is injected in a fan-like pattern both superficially and deeply in the supra-pubic region, more towards the proposed line of incision. The block is completed by infiltration of $10 \mathrm{ml}$ of the drug deep at the mid-inguinal point and another $10 \mathrm{ml}$ injected subcutaneously in the line of the proposed skin crease incision. About 15 $\mathrm{ml}$ of the solution remains, which can be used as necessary, for infiltration of the spermatic cord and around the neck of the hernial sac, or for topup of the wound area at the end of the procedure. A short time is allowed the anesthetic to take effect before starting the operation. Standard Lictenstein mesh repair was done for all the cases. Intraoperatively, in LA group, patients were asked about the pain or discomfort during operation (none, some or severe). If needed, the pain was treated by local injection of the drug solution subject to the maximum permissible dosage at the operation site. Conversion to general anesthesia was to be done if pain persisted in significant levels.

Immediately post-operatively injection Diclofenac $75 \mathrm{mg}$ IM was given to patients of both groups, subsequently putting them on oral Ibuprofen (400 mg) TDS. Post-operative pain assessment was done using a visual analog scale(VAS) immediately post-operatively, after 6 hours and after 24 hours. On a VAS score of more than $6(60 \mathrm{~mm})$, patient was given injection Diclofenac $75 \mathrm{mg}$ IM as rescue medication and was recorded. Complications such as micturition difficulties and time taken for the patient to become ambulatory was noted.

\section{Observation and Results}

This is a comparative study carried out in 60 patients with 30 patients being given spinal anaesthesia and 30 patients given local anaesthesia, admitted in surgical ward in Sir Sayajirao Hospital, Baroda from January 2007 to September 2008.

All the patients of the LA group experienced some sort of intra-operative discomfort. The mean VAS score was $18.4 \mathrm{~mm}$ (range $5-33 \mathrm{~mm}$ ). This was probably caused by touch or pressure on the surrounding non-anesthetized areas or by pulling of the spermatic cord or by the handling of the hernia sac, which was easily manageable by reassurance and additional injection of local anesthetic solution. None of the patients in the SA group experienced any intra-operative pain. 
Table 1: VAS pain scores of both the groups intra-operatively and post-operatively

\begin{tabular}{|l|c|c|c|c|c|c|c|c|c|}
\hline \multirow{2}{*}{ Group } & \multicolumn{3}{|c|}{ Intra-op } & \multicolumn{3}{c|}{6 hrs } & \multicolumn{3}{c|}{$24 \mathrm{hrs}$} \\
\cline { 2 - 10 } & Min & Max & Mean & Min & Max & Mean & Min & Max & Mean \\
\hline LA & 5 & 33 & 18.4 & 16 & 51 & 32.4 & 15 & 44 & 28.2 \\
\hline SA & 0.0 & 0.0 & 0.0 & 31 & 79 & 51.2 & 17 & 46 & 27.6 \\
\hline
\end{tabular}

Only three patients of the SA group had micturition complaints, out of which two patients had complaint of incomplete evacuation after micturition and retention due to prostatism that was managed by per-urethral catheterization. One patient had complaint of retention and inability to micturate due to excessive pain which was managed by a rescue dose of analgesic and reassurance.

Patients in LA group were ambulatory immediately after surgery as no sedation was given to the patients. Recovery from anesthesia was significantly faster for patients in the LA group than those in the SA group.

Table 2: Mean time taken by patient to become ambulatory

\begin{tabular}{|l|c|}
\hline Group & Mean Time (hrs) \\
\hline LA & 0.0 (immediate) \\
\hline SA & 4.1 \\
\hline
\end{tabular}

Table 3: Mean operative time and post-operative hospital stay

\begin{tabular}{|l|c|c|}
\hline Group & LA group & SA group \\
\hline Mean operative time & 62.8 mins & 61.5 mins \\
\hline Post-op hospital stay & 3.7 days & 3.4 days \\
\hline
\end{tabular}

\section{Discussion}

The preferred choice of anaesthesia world wide for all reducible adult inguinal hernia repairs is local. It is safe, simple, effective, and economical, without post-anesthesia side effects. The inguinal region, which includes the inguinal canal, the spermatic cord and the surrounding soft tissue structures, receives its sensory innervation from three nerves - Iliohypogastric nerve, Ilioinguinal nerve, and Genitofemoral nerve. The ilioinguinal nerve passes through the external inguinal ring, usually in close association with the spermatic cord. The genitofemoral nerve $\left(\mathrm{L}_{1,2}\right)$ supplies inguinal cord structures and the anterior scrotum via its genital branch and supplies the skin and subcutaneous tissues of the femoral triangle via the femoral branch. These nerves, and other adjacent nerves providing overlapping sensory supply, are the targets of the inguinal regional block.

The local anaesthesia produces skin anaesthesia in the line of the incision. This is best achieved by injecting local anaesthetic subcutaneously in the line of the incision. It blocks the nerve supply to the deeper tissues which are to be dissected and manipulated. It produces anaesthesia of the parietal peritoneum of the hernia and especially the neck of the sac which is very sensitive. Additionally, local anesthesia administered before the incision produces longer postoperative analgesia. It is because local infiltration, theoretically, inhibits build-up of local nociceptive molecules and, therefore, there is better pain control in the postoperative period.

In our study, pain relief was significantly better for the LA group at $6 \mathrm{hrs}$ after surgery than the SA group. However, there was no significant difference in the pain status for both the groups at 24 hrs after surgery.

Table 4: Comparison of post-operative pain in both groups in VAS scores[mm]

\begin{tabular}{|l|l|l|l|}
\hline Our study & LA group & SA group & 'p' value \\
\hline 6 hours & $32.4 \mathrm{~mm}$ & $51.2 \mathrm{~mm}$ & $<0.01$ \\
\hline 24 hours & $28.2 \mathrm{~mm}$ & $27.6 \mathrm{~mm}$ & 0.7406 \\
\hline
\end{tabular}

Van Veen et $\mathrm{al}^{(27)}$ found on analysis of postoperative visual analogue scale scores that patients operated under local anesthesia had significant less pain shortly after surgery than those under spinal anesthesia $(\mathrm{P}=0.021)$. 
Nordin et $\mathrm{al}^{(28)}$ concluded that in the early postoperative period, local anaesthesia was superior to general and regional anesthesia with respect to post-operative pain. At 8 days' and 30 days' follow-up, there were no significant differences between the three groups.

Patrick O'Dwyer et al ${ }^{(4)}$ observed that the patients in the LA group had significantly less pain on movement at 6 hours postoperatively. This effect was transient, however, and had disappeared at 24 and 72 hours.

Callesen et $\mathrm{al}^{(31)}$ derived from their study that LA provides a safe alternative to other anesthetic techniques with an acceptable rate of satisfaction, but intra-operative pain relief needs improvement. Use of two different anaesthetic agents decreases the likelihood of exceeding the therapeutic maximum dose of each individual agent. ${ }^{(14)}$

The addition of sodium bicarbonate $-1 \mathrm{mEq} / 10$ $\mathrm{mL}$ of lignocaine reportedly causes reduction in onset time by increasing the local $\mathrm{pH}$ and thereby facilitating the binding of the local anaesthetic to the target tissue. ${ }^{(14)}$

Adrenaline, when added to the anesthetic mixture, can prolong the anaesthetic time by causing local vasoconstriction and delaying the clearance of the drug from the site of action.

The only notable complication observed during this study was of micturition difficulties, which were experienced by 3 patients in the SA group compared to none in the LA group $(\mathrm{p}=0.0779)$.

Van Veen et $\mathrm{al}^{(27)}$ found that significantly more urinary retention $(\mathrm{P}<0.001)$ occurred after spinal anesthesia than local anesthesia. Ozgun et $\mathrm{al}^{(5)}, \mathrm{P}$. Sanjay et $\mathrm{al}^{(30)}$ and Young et $\mathrm{al}^{(34)}$ also concluded the same. Kark et $\mathrm{al}^{(8,41)}$, in their study of 3175 primary inguinal hernia repairs using LA, observed that there were no postoperative cases of urinary retention.

In our study, the recovery from anesthesia, in terms of ambulation after surgery, was significantly faster $(\mathrm{P}<0.01)$ for the patients in the LA group than those in the SA group.

Van Veen et $\mathrm{al}^{(27)}$ found no significant differences between the two groups with respect to the activities of daily life and quality of life. Similarly, Patrick O'Dwyer ${ }^{(4)}$ et al observed that although physical activity was significantly impaired at 24 hours, this and return to usual social activities were similar in both groups. Kark et $\mathrm{al}^{(8,41)}$ observed that overall median time of return to work across the whole group was 9 days. In all, $49.6 \%$ of office workers returned to work in 1 week or less and $61 \%$ of manual workers in 2 weeks or less.

In our study, the operative times in both the groups were found to be comparable. Thus, surgeon's satisfaction in terms of operative time was not compromised by the choice of anesthesia. Van Veen et $\mathrm{al}^{(27)}$, however, observed that the total operating time is significantly shorter in the local anesthesia group ( $p<0.001)$.

In our study, the post-operative hospital stay was similar for both the groups of patients. The duration of hospital stay was governed by the social factors and not by the choice of anesthesia. Van Veen et $\mathrm{al}^{(27)}$ reported in their study that more overnight admissions $(p=0.004)$ occurred after spinal anesthesia. Nordin et $\mathrm{al}^{(28)}$ and $P$. Subramaniam et $\mathrm{al}^{(2)}$ also concluded the same. P. Sanjay et $\mathrm{al}^{(30)}$ and Ozgun et $\mathrm{al}^{(5)}$ also reported significantly higher day-case rates under LA compared to GA.

In our study, the operative time and duration of hospital stay were similar in both the groups. The choice of anesthesia did not have a bearing on the costs incurred due to indoor hospital stay of the patient and the costs incurred in the operation theatre as ours is a government funded hospital. But, the operations performed under spinal anesthesia required the services of an anesthetist. The remuneration of the anesthetist was thus an added expenditure for the patients in the SA group. Kark et $\mathrm{al}^{(8,41)}$ found that the economic benefits are enhanced by low morbidity, early return to normal activities and low recurrence rates in case of primary inguinal hernia repairs using polypropylene mesh, under local anesthesia on an ambulatory basis. Similar observations were 
made by Patrick O'Dwyer et al ${ }^{(4)}$ and R Bernia et $\mathrm{al}^{(35)}$.

LA can be particularly useful for patients with cardiovascular or respiratory disease who could tolerate other types of anaesthesia but would be at reduced risk if given only LA. As the abdominal muscles are not paralysed in case of LA, the patient can be asked to cough intra-operatively which can help in identifying a thin sac or a sliding hernia. The absence of postoperative sedation or drowsiness allows early ambulation and diminishes the requirement for recovery facilities. ${ }^{(29)}$ Local anaesthesia provides postoperative analgesia for up to four hours. ${ }^{(7,29)}$ It may be administered by the surgeon, eliminating the need for an anaesthetist. ${ }^{(35,41)}$

However, surgery on the awake patient under local anaesthesia must be carried out gently. ${ }^{(29)}$ Incisional pain is usually blocked. Although pain sensation is usually blocked by the anaesthetic, traction on certain tissues, particularly the peritoneum, is uncomfortable. The patient should be warned that some sensation may be experienced during the operation but that it will not be painful. Larger hernias, particularly those with incarcerated bowel may prove unsuitable for local anaesthesia. ${ }^{(4)}$ Some sedation during the operation may be required for anxious patients which loses some of the benefits of avoiding general anaesthesia. ${ }^{(29)}$ Patients who are excessively nervous may be unsuitable for surgery under local anaesthesia. ${ }^{(32)}$ For similar reasons, patients of pediatric age group are not suitable for this technique.

Table 5: 'p' values showing efficacy of local anaesthesia over spinal anaesthesia in various studies

\begin{tabular}{|l|c|c|c|}
\hline Studies & Post-op pain & Complications & Hospital Stay \\
\hline Our study & $\mathrm{p}<0.01$ & $\mathrm{p}=0.079$ & $\mathrm{p}=0.085$ \\
\hline Van Veen et al & $\mathrm{p}=0.021$ & $\mathrm{p}<0.001$ & $\mathrm{p}=0.004$ \\
\hline P. Sanjay et al & $\mathrm{p}<0.05$ & $\mathrm{p}<0.05$ & $\mathrm{p}<0.05$ \\
\hline Ozgun et al & $\mathrm{p}<0.05$ & $\mathrm{p}<0.05$ & ---- \\
\hline $\begin{array}{l}\text { Uma Shrivastav } \\
\text { et al }\end{array}$ & $\mathrm{p}<0.05$ & ---- & ---- \\
\hline $\begin{array}{l}\text { P. Subramaniam } \\
\text { et al }\end{array}$ & $\mathrm{p}<0.05$ & ---- & ---- \\
\hline
\end{tabular}

\section{Conclusions}

Surgeon's satisfaction in terms of intra-operative ease, total operating time and patient's response was comparable to that of the use of spinal anesthesia. Intra-operative discomfort was experienced by few patients in the LA group, but it was easily manageable. Postoperative pain relief was better with the LA group at $6 \mathrm{hrs}$ after surgery, although there was no significant difference in pain status after 24 hrs of surgery. Recovery from anesthesia was also better for the patients of LA group as they were ambulatory immediately after surgery. Mortality after elective hernia surgery is very low, hence it is not possible to assess differences using either LA or SA in a clinical trial setting. In terms of cost effectiveness, LA is better as it eliminates the need for an anaesthetist. Moreover, surgery under LA offers us the option to treat the patient on a day care basis, thus further reducing the cost, making it comparatively more effective and useful.

\section{References}

1. Kehlet $\mathrm{H}$ and White PF. Optimizing anaesthesia for inguinal herniorrhaphy: General, Regional or local anaesthesia? Anesth Analg 2001; 93: 1367 - 9

2. Subramaniam P, Leslie J Gourlay C, Clezy JK. Inguinal hernia repair: A comparison between local and general anaesthesia. Aust NZJ Surg 1998; 68: 799 - 800

3. Callesen $\mathrm{T}$, Bech $\mathrm{K}$, Kehlet $\mathrm{H}$. The feasibility, safety and cost of infiltration anaesthesia for hernia repair. Anaesthesia 1998; 53: 31-5

4. O' Dwyer PJ, Serpell MG, Millar K, et al. Local or general anaesthesia for open hernia repair. A randomized trial. Annals of Surgery 2003; 237: 574-9

5. Ozgun H, Kurt MN, Kurt 1, Cevikel MH. Comparison of local, spinal and general anaesthesia for inguinal herniorrhaphy, Eur J Surg 2002; 168: 455 - 9

6. Callesen $\mathrm{T}$, Bech $\mathrm{K}$, Kehlet $\mathrm{H}$. One thousand consecutive inguinal hernia 
repairs under unmonitored local anaesthesia. Anesth Analg 2001; 93: 1373 $-61$

7. Amid PK, Shulman AG, Lichtenstein IL. Local anesthesia for inguinal hernia repair step-by-step procedure. Ann Surg 1994; 220:735-7.

8. Kark AE, Kurzer MN, Belsham PA. Three thousand one hundred seventy-five primary inguinal hernia repairs: advantages of ambulatory open mesh repair using local anesthesia. J Am Coll Surg 1998;186:447-55

9. Schwartz's Principles of Surgery, 8th edition, Ch. 36

10. Russell RH: The saccular theory of hernia and the radical operation. Lancet 3: 1197, 1906

11. Rodrigues-Junior AJ, de-Tolosa EM, de Carualho CA: Electron microscopic study on the elastic and elastic related fibres in the human fascia transversalis at different ages. Gegenbaurs Morphol Jahrb 1990; 136:645

12. Cannon DJ, Read RC: Metastatic emphysema: A mechanism for acquiring inguinal herniation. Ann Surg 194:270, 1981

13. Arnbjornsson E: Development of right inguinal hernia after appendectomy. Am J Surg 143:174, 1982

14. Lee's Synopsis of Anesthesia, 13th edition, Ch. 4.1

15. Cattterall WA (2002): Molecular mechanisms of gating and drug block of sodium channels" - Novartis Found Symp 241: 206-32

16. J. P. Howard Fee, J. G. Bovill - Pharmacology for Anaesthesiologists, Ch. 5

17. Rosenblatt MA, Abel M, Fischer GW, Itzkovich CJ, Eisenkraft JB. Successful Use of a $20 \%$ lipid emulsion to resuscitate a patient after a presumed bupivacainerelated cardiac arrest. Anesthesiology 2006;105:217-8
18. Picard J, Meek T. Lipid emulsion to treat overdose of local anaesthetic: the gift of the glob. Anaesthesia 2006;61:107-9

19. Nyhus LM, Condon RE: Hernia, 3rd edition, Philadelphia: JP Lippincott, 1989

20. Abrahamson J: Maingot's Abdominal Operations, 10th edition, Appleton and Lange, 1997; 479-572

21. Shouldice EE. The treatment of hernia. Ontario Med Rev 1953; 20:670

22. McVay CB, Halverson K. Preperitoneal hernioplasty. In: Beahrs OH, Beart RW Jr, General Surgery Therapy. New York: John Wiley and Sons; 1981:10

23. Abrahamson J, Eldar S. Primary and recurrent inguinal hernias - repair with nylon darn. Theor Surg 1987; 2:91

24. Stoppa RE, Rives JL, et al. The use of Dacron in the repair of hernias of the groin. Surg Clin North Am 1984; 64:269

25. Lichtenstein IL, Shulman AG, Amid PK. The cause, prevention, and treatment of recurrent groin hernia. Surg Clin North Am 1993; 73:529

26. Ger R: The management of certain abdominal hernia by intra-abdominal closure of the neck of the sac. Preliminary communication. Ann R Coll Surg Engl 64:342, 1982

27. van Veen RN, Mahabier C, Dawson I, Hop WC, Kok NF, Lange JF, Jeekel J - Spinal or local anesthesia in Lichtenstein hernia repair: a randomized controlled trial : Ann Surg. 2008; 247(3):428-33

28. Nordin P, Zetterstrom H, Gunnarsson U, et al - Local, regional or general anesthesia in groin hernia repair: multicentre randomized trial. Lancet 2003; 362:853

29. Uma Srivastava, Aditya Kumar, Surekha Saxena, Neeraj, Deepankar Raj Sehgal Comparison of Local, Spinal and General Anaesthesia for Inguinal Hernia Repair: J Anesth Clin Pharmacology 2007; 23(2): $151-154$ 
30. P Sanjay, A Woodward - Inguinal hernia repair: local or general anaesthesia? : Ann R Coll Surg Engl 2007; 89: 497-503

31. Callesen T, Bech K, Kehlet H - One Thousand Consecutive Inguinal Hernia Repairs Under Unmonitored Local Anesthesia: Anesth Analg 2001;93:1373-6

32. Gnanalingham K, Misra B - Day case hernia repair under local versus general anaesthesia: patient preferences : Ambulatory Surgery Volume 6, Issue 4, October 1998, Pages 227-229

33. Ezio Gianetta, Sonia Cuneo, Bruno Vitale, Giovanni Camerini, Paola Marini, Mattia Stella, MD - Anterior Tension-Free Repair of Recurrent Inguinal Hernia Under Local Anesthesia - A 7-Year Experience in a Teaching Hospital : Ann Surg Vol. 231, No. 1, 132-136

34. Young DV - Comparison of local, spinal and general anaesthesia for inguinal herniorrhaphy : Am J Surg 1987; 153: 560-3

35. Bernia R, Hashemi F, Stryker SJ, et al - A comparison of general versus local anesthesia during inguinal herniorrhaphy : Surg Gynecol Obstet.1992;174:277-280

36. Makuria T, Alexander-Williams J, Keighley MRB - Comparison between general and local anesthesia for repair of groin hernias : Ann Roy Coll Surg Engl. 1979;61:291-294

37. Baskerville PA, Jarret PEM - Day case inguinal hernia : Ann R Coll Surg Engl 1983; 65: 224-5

38. H Lau, F Lee - An audit of the early outcomes of ambulatory inguinal hernia repair at a surgical day-care centre : HKMJ 2000;6:218-20

39. N. Masiira - Experience with day-care surgery in a Private Surgical Clinic in Nakuru, Kenya : East and Central African Journal of Surgery, 2001, Vol 6-02
40. Dhumale R - Feasibility study of hernia surgery in a general practice setting : $\mathrm{Br} \mathrm{J}$ Gen Pract 2004 August 1; 54(505): 604607

41. Bapat R; Kantharia CV; Ranka S; Bakshi G; Iyer A - Day care surgery in a public hospital set up : Bombay Hospital Journal. 2001 Apr; 43: 249-52

42. Colin A. Pinnock, Ted Lin, Tim Smith, Robert Jones Fundamentals of Anesthesia, 2nd edition, $\mathrm{Ch} 7$

43. Amid PK, Lichtenstein IL. Long term result and current status of the Lichtenstein open tension-free hernioplasty. Hernia 1998; 2: 89-94.

44. Amid PK, Shulman AG, Lichtenstein IL. Open tension free repair of inguinal hernias: the Lichtenstein technique. Eur J Surg 1996; 162: 447-53.

45. Kark AE, Kurzer M, Waters KJ. Tension free hernia repair: review of 1098 cases using local anaesthesia in a day case unit. Ann R Coll Surg Engl 1995; 77: 299-304.

46. Welsh DR, Alexander MA: The Shouldice repair. Surg Clin North Am 1993; 73: 451-69.

47. Stobie B: Shouldice Hospital: dedicated to the repair of hernias. Can Oper Room Nurs J 1999; 17: 30-2.

48. Kingsnorth AN, Porter C, Bennet DH. The benefit of a hernia service in a public hospital. Hernia 2000; 4: 1-5.

49. Bailey and Love's Short Practice of Surgery, 24th edition, Ch. 17. 